\title{
Ischemic heart disease among subjects with and without chronic obstructive pulmonary disease - ECG-findings in a population-based cohort study
}

\author{
Ulf Nilsson ${ }^{1,3^{*}}$, Bengt Johansson ${ }^{1}$, Berne Eriksson², Anders Blomberg ${ }^{1}$, Bo Lundbäck² and Anne Lindberg ${ }^{1}$
}

\begin{abstract}
Background: Cardiovascular comorbidity in COPD is common and contributes to increased mortality. A few population-based studies indicate that ischemic electrocardiogram (ECG)-changes are more prevalent in COPD, while others do not. The aim of the present study was to estimate the presence of ischemic heart disease (IHD) in a population-based COPD-cohort in comparison with subjects without COPD.

Methods: All subjects with obstructive lung function (COPD, $n=993)$ were identified together with age- and sex-matched controls (non-COPD, $n=993$ ) from population-based cohorts examined in 2002-04. In 2005, data from structured interview, spirometry and ECG were collected from 1625 subjects. COPD was classified into GOLD 1-4 after post-bronchodilator spirometry. Ischemic ECG-changes, based on Minnesota-coding, were classified according to the Whitehall criteria into probable and possible IHD.

Results: Self-reported IHD was equally common in COPD and non-COPD, and so were probable and possible ischemic ECG-changes according to Whitehall. After excluding subjects with restrictive spirometric pattern from the non-COPD-group, similar comparison with regard to presence of IHD performed between those with COPD and those with normal lung-function did neither show any differences. There was a significant association between self-reported IHD ( $p=0.007)$ as well as probable ischemic ECG-changes $(p=0.042)$, and increasing GOLD stage. In COPD there was a significant association between level of $\mathrm{FEV}_{1}$ percent of predicted and self-reported as well as probable ischemic ECG-changes, and this association persisted for self-reported IHD also after adjustment for sex and age.
\end{abstract}

Conclusion: In this population-based study, self-reported IHD and probable ischemic ECG-changes were associated with COPD disease severity assessed by spirometry.

Keywords: Comorbidity, Epidemiology, Coronary disease, Respiratory diseases

\section{Background}

The prevalence of chronic obstructive pulmonary disease (COPD) is approximately $10 \%$, and there is still a significant under-diagnosis with up to $80 \%$ of the cases not yet identified by healthcare [1-3]. COPD is associated with several comorbidities whereof cardiovascular disease (CVD) is the most common [4] and both of

\footnotetext{
* Correspondence: ulf.nilsson@umu.se

'Department of Public Health and Clinical Medicine, Division of Medicine, Umeå University, Umeå, Sweden

${ }^{3}$ Department of Public Health and Clinical Medicine, Division of Medicine, University Hospital of Northern Sweden, Umeå 90185, Sweden

Full list of author information is available at the end of the article
}

these conditions are among the leading causes of death worldwide [5, 6]. The associations between COPD and CVD are complex; besides sharing common risk factors such as smoking and aging $[7,8]$, also systemic inflammation is suggested as a possible link between the conditions $[9,10]$.

Among cardiovascular diseases, ischemic heart disease (IHD) is of particular interest. . According to the WHO, globally IHD was responsible for 7.5 million out of the total 17.4 million CVD deaths in 2012. Hospital-based studies have shown that IHD is common among subjects with COPD [11, 12] and there is an increased risk for 
death after a myocardial infarction among those with COPD compared to those without [13-15]. A recently published review clearly shows that IHD worsens the disease progress as well as prognosis among subjects with COPD $[5,6,16]$. However, the under-diagnosis of COPD most probably contributes to an underestimation of the real impact of IHD among subjects with COPD in the general population. Simple diagnostics signs of IHD in COPD, such as ischemic findings on electrocardiogram (ECG), have hardly been evaluated in populationbased studies.

The aim of this population-based study was to estimate the prevalence of self-reported ischemic heart disease and ischemic ECG changes among subjects with COPD in comparison with subjects without obstructive lung function impairment, divided into normal lung function and restrictive pattern. Our hypothesis was that the prevalence of IHD would be higher among subjects with COPD compared with subjects with normal lung function and that the prevalence of IHD would increase with COPD disease severity, as assessed by spirometry.

\section{Methods}

\section{Study population}

Four population-based cohorts from the Obstructive Lung Disease in Northern Sweden (OLIN) studies were re-examined during 2002-2004. All subjects with obstructive lung function impairment (COPD) were identified $(n=993)$ together with an age- and sexmatched reference population without obstructive lung function impairment. The study population $(n=1986)$ has since 2005 been invited to annual examinations with a basic program including spirometry and structured interview [17].

This study is based on data collected in 2005 when ECG recordings were performed in addition to the basic program. In total, 1641 participated whereof 1625 had complete data on spirometry, structured interview and ECG. The structured interview questionnaire included questions validated in national and international studies [18-21]. The Regional Ethics Committee at Umeå University approved the study (approval number 04-045 M), which was carried out according to the declaration of Helsinki. Written informed consent for participation in the study was obtained from all participants.

\section{Definitions}

Self-reported IHD was based on data from the structured interview, and was defined as any history of angina pectoris, myocardial infarction, coronary artery bypass surgery (CABG) or percutaneous coronary intervention. Hypertension was defined by affirmative answer to the question "Do you have high blood pressure?" Body mass index (BMI) was calculated and classified in four groups (underweight $<20$, normal 20-24.9, overweight $\geq 25$ 29.9 and obesity $\geq 30 \mathrm{~kg} / \mathrm{m}^{2}$ ). Smoking habits were classified as non-smoker, ex-smoker (stopped since at least 12 months) and smokers, as well as by pack years.

\section{Electrocardiogram}

Standard twelve-lead ECG's were recorded before spirometry, on subjects in the supine position and after sufficient rest. Two independent physicians analyzed all ECG recordings according to the Minnesota code (MC) and both of them were blinded to COPD status and spirometry values. ECG-based IHD was defined in accordance to the Whitehall criteria as probable IHD; major Q/QS wave (MC 1.1-1.2) and left bundle branch block (LBBB) (MC 7.1.1). Possible IHD was defined as minor $\mathrm{Q} / \mathrm{QS}$ wave (MC 1.3), ST segment depression (MC 4.1-4.3), and T wave items (MC 5.1-5.3) [22].

\section{Lung function tests}

Lung function test was performed in accordance with the American Thoracic Society guidelines [23], following ECG registration, using a dry volume spirometer, the Vicatest 5 (Gebr. Mijnhardt B.V., Odijk, Netherlands). Vital capacity (VC) was defined as the highest value of forced vital capacity (FVC) and slow vital capacity (SVC) pre- or post- reversibility test. Reversibility test was performed with Ventoline $4 \times 0.2 \mathrm{mg}$ if $\mathrm{FEV}_{1} / \mathrm{VC}<0.70$ or if $\mathrm{FEV}_{1}<80 \%$ of predicted value. COPD was defined as $\mathrm{FEV}_{1} / \mathrm{VC}<0.70$ using the best values of $\mathrm{VC}$ and $\mathrm{FEV}_{1}$ pre- or post-reversibility test. Severity of airflow limitation in COPD was classified according to the Global Initiative for Chronic Obstructive Lung Disease (GOLD) document; GOLD 1-4 based on $\mathrm{FEV}_{1} \%$ predicted [24]. The OLIN reference values, based on healthy nonsmokers, were applied [25, 26].

The reference population without obstructive lung function impairment, defined as $\mathrm{FEV}_{1} / \mathrm{VC} \geq 0.70$, was further divided into subjects with normal lung function (NLF), $\mathrm{FEV}_{1} / \mathrm{VC} \geq 0.70$ and $\mathrm{VC}>80 \%$, and subjects with restrictive pattern on dynamic spirometry defined as $\mathrm{FEV}_{1} / \mathrm{VC} \geq 0.70$ and $\mathrm{VC}<80 \%$ of predicted.

\section{Statistics}

Statistical calculations were performed using the Statistical Package for the Social Sciences (SPSS) software version 21.0 (IBM, Armonk, NY, USA). Missing data on smoking habits and self-reported cardiovascular disease in a total of 4 subjects were collected from data from the previous and/or following year's examinations. The chi-square test was used for categorical variables and bivariate comparisons. Mantel-Haenszel test for trend and Fischer's exact test was used where appropriate. Independent sample $t$-test and ANOVA were used to 
compare means. Association between the continuous variable $\mathrm{FEV}_{1}$ percent of predicted and self-reported IHD respectively probable and possible ischemic ECG changes according to Whitehall was analyzed by bivariate logistic regression with each of the IHD variables as dependent variable. Analyses were also performed in similar models adjusting for age and sex. P-values $<0.05$ were considered statistically significant.

A cross-sectional analysis of COPD and non-obstructive lung function based on spirometry in 2005 was performed. A further analysis was performed in which the subjects had to fulfill the spirometric criteria of COPD vs. nonCOPD not only in 2005 but also at baseline, i.e. at recruitment in 2002-04 and defined as "stable COPD" and "stable non-COPD". Those with non-COPD were further divided into restrictive pattern and NLF.

\section{Results}

\section{Characteristics of the study population in 2005}

Among all subjects with complete data on spirometry, interview and ECG in 2005, 634 subjects out of 1625 fulfilled the spirometric criteria of COPD. Basic characteristics are presented in Additional file 1. The burden of tobacco smoking, assessed as smoking habits as well as pack years, was significantly higher among COPD-subjects.

There was no significant difference in the prevalence of self-reported IHD when comparing non-COPD and COPD, although myocardial infarction was significantly more common among COPD-subjects and CABG was more common among non-COPD-subjects. Ischemic ECG changes, analyzed separately or categorized according to Whitehall, were similarly common in non-COPD and COPD (Additional file 2).

\section{Characteristics of stable non-COPD and stable COPD Comparing subjects with normal lung function and subjects with restrictive pattern}

Among subjects classified as non-COPD, $\mathrm{FEV}_{1} / \mathrm{VC}$ $\geq 0.70$, both at baseline and in $2005(n=757), 145$ subjects had a restrictive pattern on dynamic spirometry. Subjects with restrictive pattern had higher BMI and higher prevalence of diabetes, hypertension, angina, myocardial infarction and arrhythmias compared to subjects with NLF (Table 1).

\section{Comparing subjects with normal lung function and subjects with COPD}

Basic characteristics comparing subjects with $\mathrm{FEV}_{1} / \mathrm{VC}$ ratio $<0.70$ both at baseline and in $2005(n=576)$ and subjects with NLF at both occasions $(n=612)$ are given in Table 1. Subjects with COPD were older, had a lower mean BMI, and the burden of tobacco smoking was higher considering both current smoking and pack years
(Table 1). The distribution of COPD by GOLD classification was: GOLD 1, $n=221$ (38.4 \%), GOLD 2, $n=308$ $(53.5 \%)$ and GOLD 3-4, $n=47$ (8.2 \%).

The prevalence of self-reported IHD was $16.1 \%$ among COPD and $12.6 \%$ among subjects with NLF $(p=0.08)$. Myocardial infarction was significantly more common among those with COPD compared with NLF (Table 1).

\section{Ischemic ECG findings \\ Comparing subjects with normal lung function and subjects with COPD}

The prevalence of ischemic ECG changes, defined as Q/QS wave, ST segment depression, $\mathrm{T}$ wave items and left bundle branch block, was similar among subjects with COPD and NLF, also when ischemic ECG changes were divided into major, intermediate and minor (Table 2).

When ischemic ECG changes were analysed in groups according to the Whitehall criteria, "any IHD" had similar prevalence among subjects with NLF and COPD, $22.9 \%$ and $24.7 \%$ respectively. The subgroups "probable IHD" and "possible IHD" were also equally prevalent among subjects with COPD and subjects with NLF (Table 2).

\section{Ischemic heart disease in relation to COPD severity}

The prevalence of self-reported IHD was higher in GOLD 2 compared with in subjects with NLF (Fig. 1a), and the test for trend NLF - GOLD 3-4 was significant $(p=0.007)$. When comparing the prevalence of ischemic ECG-changes in each of the GOLD stages with the prevalence among those with NLF, there were no differences within any of the Whitehall groups (Fig. 1b, c). Test for trend in NLF - GOLD 3-4 was significant in subjects with Whitehall probable IHD $(p=0.042)$, but not among Whitehall possible IHD $(p=0.355)$.

In a logistic regression analysis, $\mathrm{FEV}_{1}$ percent of predicted value was significantly associated with selfreported IHD and probable ischemic ECG-changes according to Whitehall, but not possible ischemic ECG changes according to Whitehall (Table 1). When adjusting for age and sex, the association between $\mathrm{FEV}_{1}$ percent of predicted value and self-reported IHD persisted, while the association with ischemic ECG-changes corresponding to Whitehall probable IHD was lost (Table 3).

\section{Discussion}

In this cross sectional population based study, selfreported as well as ECG changes of ischemic heart disease (IHD) according to Whitehall were equally prevalent among subjects with COPD and those with normal lung function (NLF). There was a significant association between increasing presence of self-reported IHD as well as probable ECG changes of IHD, according to the 
Table 1 Basic characteristics. Comparing subjects with normal lung function (NLF) vs. restrictive pattern and normal lung function vs. COPD. Analyses were performed among subjects "stable non-COPD" (NLF and restrictive pattern) and "stable COPD); at baseline and in 2005 (significant values in bold)

\begin{tabular}{|c|c|c|c|c|c|c|}
\hline Categories & Variables & NLF $n=612$ & Restrictive pattern $n=145$ & $P^{c}$ & $\operatorname{COPD} n=576$ & $P^{d}$ \\
\hline \multicolumn{7}{|l|}{ Sex } \\
\hline & Women, n (\%) & $292(47.7)$ & $60(41.4)$ & 0.17 & $243(42.2)$ & 0.06 \\
\hline \multicolumn{7}{|l|}{ Age } \\
\hline & Mean (SD) & $64.8(11.0)$ & $68.6(10.1)$ & $<0.001$ & $66.6(10.6)$ & 0.004 \\
\hline \multicolumn{7}{|l|}{ BMI } \\
\hline & Mean (SD) & $27.1(4.0)$ & $28.4(4.4)$ & 0.001 & $26.3(4.1)$ & 0.001 \\
\hline & Underweight <20, n (\%) & $6(1.0)$ & $4(2.8)$ & & $22(3.8)$ & \\
\hline & Normal 20-24.9, n (\%) & $194(31.7)$ & $27(18.8)$ & & $204(35.4)$ & \\
\hline & Overweight 25-29.9, n (\%) & $290(47.4)$ & $68(47.2)$ & & $259(45.0)$ & \\
\hline & Obese $\geq 30, \mathrm{n}(\%)$ & $122(19.9)$ & $45(31.3)$ & & $91(15.8)$ & \\
\hline \multicolumn{7}{|c|}{ Smoking habits } \\
\hline & Pack years, mean (SD) & $6.5(10.3)$ & $6.8(11.3)$ & 0.74 & $17.0(16.2)$ & $<0.001$ \\
\hline & Current smoker, n (\%) & $71(11.6)$ & $13(9.0)$ & & $207(35.9)$ & \\
\hline & Ex smoker, n (\%) & $234(38.2)$ & $52(35.9)$ & & $241(41.8)$ & \\
\hline & Non smoker, n (\%) & $307(50.2)$ & $80(55.2)$ & & $128(22.2)$ & \\
\hline \multicolumn{7}{|c|}{ Comorbidities $^{\mathrm{a}}$} \\
\hline & Diabetes, n (\%) & $47(7.7)$ & $26(17.9)$ & $<0.001$ & $49(8.5)$ & 0.60 \\
\hline & Hypertension, n (\%) & $197(32.2)$ & $69(47.6)$ & 0.001 & $198(34.4)$ & 0.42 \\
\hline & Angina pectoris, n (\%) & $67(10.9)$ & 27 (18.6) & 0.01 & $70(12.2)$ & 0.521 \\
\hline & Myocardial infarction, n (\%) & $14(2.3)$ & $12(8.3)$ & 0.001 & $32(5.6)$ & 0.004 \\
\hline & CABG, n (\%) & $18(2.9)$ & $7(4.8)$ & 0.25 & $10(1.7)$ & 0.17 \\
\hline & $\mathrm{PCl}, \mathrm{n}(\%)$ & $8(1.3)$ & $5(3.4)$ & 0.07 & $8(1.4)$ & 0.90 \\
\hline & Arrhythmias, n (\%) & $44(7.2)$ & $20(13.8)$ & 0.01 & $46(8.0)$ & 0.60 \\
\hline & Reported IHD ${ }^{\mathrm{b}}, \mathrm{n}(\%)$ & 77 (12.6) & $32(22.1)$ & 0.005 & $93(16.1)$ & 0.08 \\
\hline
\end{tabular}

${ }^{a}$ Based on interview data. ${ }^{b}$ Self-reported IHD, includes any of angina pectoris, myocardial infarction, CABG and PCI

$\mathrm{P}^{\mathrm{c}}$ comparison between normal lung function and restrictive pattern $\mathrm{P}^{\mathrm{d}}$ comparison between normal lung function and COPD

Whitehall criteria, in relation to COPD disease severity, both classified according to GOLD stage as well as assessed as $\mathrm{FEV}_{1}$ percent of predicted. The significant relationship between $\mathrm{FEV}_{1}$ percent of predicted and selfreported IHD but not probable ECG-findings remained after adjustment for age and sex.

According to a recent review, the prevalence of coronary heart disease (CHD) in different COPD populations varies between $4.7 \%$ and up to $60 \%$ [27]. Since the recruitment of study population, as well as the definitions of CHD and COPD, vary between the studies, it is difficult to compare the results. In a Danish populationbased study [28], the prevalence of IHD was $8.6 \%$ in non-COPD and increased in COPD by GOLD stage 1, 2 and $3-4 ; 12.1 \%, 14.9 \%$ and $13.7 \%$ respectively; the corresponding prevalences of Q-wave (major + minor) were $2.7 \%$ in non-COPD, and $3.3 \%, 6.2 \%$ and $6.9 \%$ by GOLD stages. Overall, self-reported heart disease and presence of corresponding ECG-findings were markedly more common in our study compared with in the Danish survey. One possible explanation for the observed difference is that although the COPD classification in the Danish study was based on spirometry, they used pre-bronchodilator values, i.e. not following current guidelines recommending post-bronchodilator spirometry for the diagnosis of COPD. Other studies have shown that the use of pre-bronchodilator spirometry misclassify up to $27 \%$ of non-obstructive subjects as obstructive, which might contribute to the lower IHD prevalence [29]. Further, the Danish study was a close to 25-year follow-up of the large-scale Copenhagen City Heart study (with the addition of a smaller random sample of younger adults) and a healthy survivor effect can thus be expected to have affected the results. In a population-based study using the Burden of Obstructive Lung Disease (BOLD) survey, close to 100 cases of COPD were identified based on post-bronchodilator spirometry and they found no increased risk for self-reported 
Table 2 Ischemic ECG changes comparing subjects with normal lung function and COPD

\begin{tabular}{|c|c|c|c|c|}
\hline & & NLF $n=612$ & COPD $n=576$ & $P$ \\
\hline \multicolumn{5}{|l|}{ Ischemic ECG changes } \\
\hline \multirow[t]{3}{*}{ Q-Waves } & Any, n (\%) & $49(8.7)$ & $48(8.3)$ & 0.64 \\
\hline & Major Q/QS, n (\%) & $20(3.4)$ & $24(4.2)$ & 0.42 \\
\hline & Minor Q/QS, n (\%) & $29(4.9)$ & $24(4.2)$ & 0.66 \\
\hline \multirow[t]{4}{*}{ ST-segment depressions } & Any, n (\%) & $39(6.4)$ & $33(5.7)$ & 0.23 \\
\hline & Major, n (\%) & $4(0.7)$ & $4(0.7)$ & 0.94 \\
\hline & Intermediate, n (\%) & $20(3.3)$ & $18(3.1)$ & 0.88 \\
\hline & Minor, n (\%) & $15(2.5)$ & $11(1.9)$ & 0.52 \\
\hline \multirow[t]{4}{*}{ T- wave items } & Any, n (\%) & $98(16.0)$ & $100(17.4)$ & 0.53 \\
\hline & Major, n (\%) & $2(0.4)$ & $1(0.2)$ & 1.00 \\
\hline & Intermediate, n (\%) & $44(7.9)$ & $45(8.7)$ & 0.64 \\
\hline & Minor, n (\%) & $52(9.2)$ & $54(9.4)$ & 0.56 \\
\hline Bundle branch block & $\operatorname{LBBB}^{\mathrm{a}}, \mathrm{n}(\%)$ & $10(1.9)$ & $11(2.3)$ & 0.68 \\
\hline \multicolumn{5}{|l|}{ Whitehall criteria } \\
\hline \multirow[t]{3}{*}{ Ischemic heart disease } & Any, n (\%) & $140(22.9)$ & $142(24.7)$ & 0.47 \\
\hline & Probable $^{\mathrm{b}}, \mathrm{n}(\%)$ & $27(5.4)$ & $35(6.1)$ & 0.19 \\
\hline & Possible $^{c}, \mathrm{n}(\%)$ & $113(19.3)$ & 107 (18.6) & 0.85 \\
\hline
\end{tabular}

${ }^{\mathrm{a}}$ Left bundle branch block. ${ }^{\mathrm{b}}$ Including Major Q/QS and LBBB. Including Minor Q/QS, any ST-segment depression and any T-wave item

cardiovascular disease or hypertension in either of the GOLD-stages [30]. In general, population based data on CHD among subjects with COPD identified by postbronchodilator spirometry is mainly self-reported, and other clinical findings of CHD, such as ECG-changes, have rarely been evaluated.

A population-based COPD-cohort, such as in our study, will include a majority of subjects with GOLD 1 and 2 and only a low number of subjects with GOLD 34 [1]. Self-reported IHD as well as ischemic ECGfindings according to the Whitehall criteria clearly increased by GOLD stage and were considerably more common in GOLD 3-4 than among subjects with mild COPD. Even though our study include a large COPDcohort, almost comparable to that of the National Health and Nutrition Examination Survey (NHANES) I [31], the distribution of GOLD stages contributes to a lack of power to show statistical significance due to the small proportion of severe/very severe COPD in a population based study, as also demonstrated by the quite large confidence intervals in Fig. 1. However, each of the GOLD stages include rather wide ranges of $\mathrm{FEV}_{1} \%$ predicted, and the continuous variable $\mathrm{FEV}_{1} \%$ predicted may be useful when it comes to evaluating events in relation to disease severity. The found positive associations between level of $\mathrm{FEV}_{1}$ among COPD-subjects and selfreported IHD as well as probable ischemic ECG-changes according to the Whitehall criteria, thus further support a relationship between IHD and COPD disease severity. Interpretation of the results is that higher $\mathrm{FEV}_{1}$ is protective, consequently, the presence of IHD increase the lower $\mathrm{FEV}_{1}$ is, i.e. by increasing COPD disease severity. Furthermore, the observed high prevalence of ischemic ECG-changes in more severe COPD disease is comparable with findings from studies using hospitals records including severe stages of COPD [11, 12, 32].

It has also been observed that subjects with COPD have increased arterial stiffness [33], which is considered a marker of early atherosclerosis and a risk factor for development of CVD. In a recent review it was even suggested that measurements of arterial stiffness should be included in routine health care to assess the risk for CVD among subjects with COPD [34]. We have previously shown that central arterial stiffness is higher in GOLD 3-4 than in non-COPD [35] also in a population based study, which is in line with the current findings of IHD being most prevalent in GOLD 3-4. The clinical implication may be that not only non-invasive measurements of arterial stiffness, but also ECG may be of value when evaluating risk for and presence of cardiovascular disease when diagnosing subjects with COPD. The underlying pathological mechanism by concomitant COPD and IHD is, however, not fully understood, but may be related to systemic inflammation and endothelial dysfunction $[5,6,16]$, and in addition high on-treatment platelet reactivity has been discussed as reason for the observed worsened prognosis among subject with concomitant COPD and IHD [5, 6, 36].

The original design of the study defined cases and sex and age-matched controls based on spirometry (COPD 
a

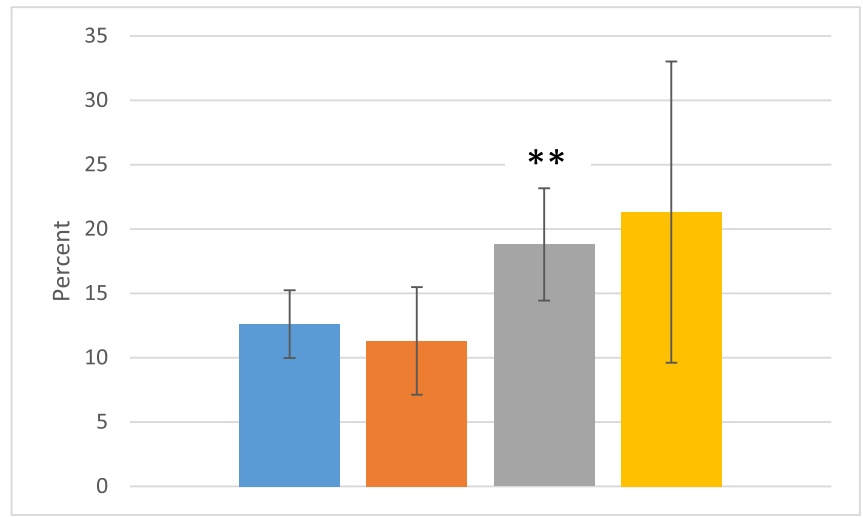

NLF GOLD 1 GOLD 2 GOLD 3-4

Self-reported IHD

b

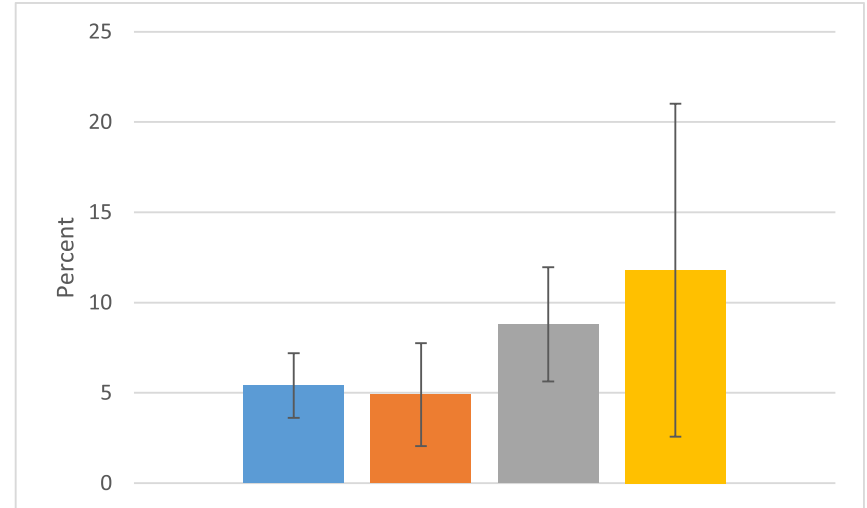

NLF GOLD $1 \quad$ GOLD 2 GOLD 3-4

Probable IHD

C

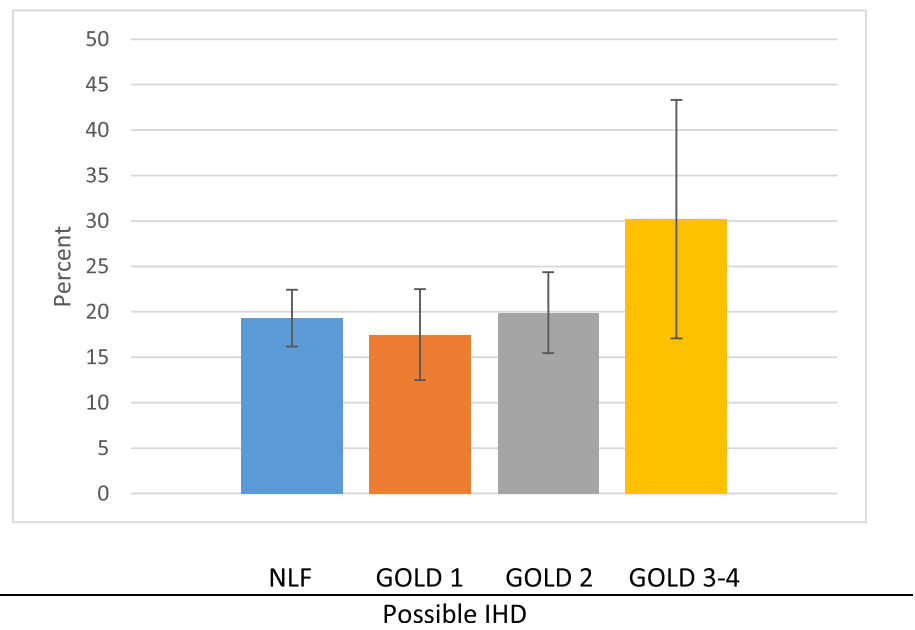

Fig. 1 Ischemic heart disease categorized as (a) Self-reported IHD and (b) Ischemic ECG changes according to Minnesota coding categorized as probable Whitehall criteria and (c) Possible Whitehall criteria among subjects with normal lung function (NLF), COPD GOLD 1, 2 and 3-4, with $95 \%$ confidence intervals. Significance is shown with ${ }^{* *} p \leq 0.01$ (NLF compared with GOLD 1, 2 and 3-4, respectively). Observe that $\mathbf{a}$, $\mathbf{b}$ and $\mathbf{c}$ have different scales on the $y$-axis 
Table 3 Logistic regression analysis of self-reported ischemic disease, probable and possible ischemic heart disease by Whitehall criteria in relation to $\mathrm{FEV}_{1}$ percent of predicted value among subjects with COPD. (significant values in bold)

\begin{tabular}{llllllll}
\hline & \multicolumn{2}{l}{ Reported IHD } & \multicolumn{2}{l}{ Probable IHD } & \multicolumn{2}{l}{ Possible IHD } \\
\hline & OR & $95 \% \mathrm{Cl}$ & OR & $95 \% \mathrm{Cl}$ & OR & $95 \% \mathrm{Cl}$ \\
FEV1 \% pred & $\mathbf{0 . 1 3}$ & $\mathbf{0 . 0 3 - 0 . 4 8}$ & $\mathbf{0 . 1 0}$ & $\mathbf{0 . 0 1 - 0 . 7 9}$ & 0.41 & $0.11-1.48$ \\
FEV1 \% pred & $\mathbf{0 . 2 2}$ & $\mathbf{0 . 0 6 - 0 . 8 5}$ & 0.24 & $0.03-1.97$ & 0.55 & $0.15-2.04$ \\
\hline
\end{tabular}

${ }^{a}$ Adjusted for age and sex

and non-COPD) in 2002-04. It has been described in other COPD studies that a proportion of the study population will transfer mainly from COPD to nonCOPD but also vice versa during follow up [37]. To address this potential bias, data from 2005 is presented as a straight cross-sectional analysis defining COPD and non-COPD by current spirometry, but also by presenting data when the subjects had to fulfill the spirometric criteria of either COPD or non-COPD not only in 2005 but also at baseline, i.e. at recruitment in 2002-04. Among subjects with non-obstructive pulmonary function, also subjects with a restrictive pattern on dynamic spirometry were included. Restrictive pattern has in previous studies been shown to associate with metabolic disorders such as diabetes, as well as a higher prevalence of IHD [38] or risk for cardiovascular disease [30]. Thus we divided non-COPD into NLF and restrictive spirometric pattern and compared subjects with COPD with those having NLF.

A limitation of this study is that the self-reported burden of comorbid conditions, in this study specifically ischemic heart disease, may be affected by recall bias as well as misclassification since interview data were not verified by medical records, even though literature has shown a good agreement between self-reported diabetes, hypertension and myocardial infarction, but not heart failure [39]. Further, a 12-lead ECG only gives a short glimpse of the electrical activity of the heart, and has limited sensitivity and specificity for detecting ischemic myocardial events. Different ischemic ECG changes, for example ST segment changes and those involving the Twaves, have great variations in sensitivity and specificity, are dynamic and may thus vary over time [40, 41]. However, the strength of this epidemiological study is the large sample size, the distribution of disease severity representative for COPD in the general population [31, 42], the use of standardized post-broncho-dilator spirometry for defining COPD in accordance with the GOLD document [24], and double blinded Minnesota coded ECGs. To the best of our knowledge, this is the first population-based study addressing ischemic heart disease among subjects with COPD using validated and generally recommended classifications of ECG-findings and COPD.

\section{Conclusions}

In this population-based study, ischemic heart disease was equally common among subjects with COPD and those with normal lung function. Among subjects with COPD, there was a significant association between higher prevalence of self-reported ischemic heart disease and the results also indicate that there is an association between ECG changes of ischemic heart disease and increasing disease severity, as assessed by level of FEV $\mathrm{F}_{1}$. A longitudinal follow-up is important to evaluate the prognostic value as well as progression of the observed ECG-findings among subjects with and without COPD.

\section{Additional files}

Additional file 1: Basic characteristics, reported respiratory symptoms and comorbidities of all subjects $(n=1625)$, comparing non-COPD and COPD. (PDF 163 kb)

Additional file 2: Ischemic ECG changes in all subjects $(n=1625)$, comparing non-COPD and COPD. (PDF $92 \mathrm{~kb}$ )

\section{Abbreviations}

BMI: body mass index; CABG: coronary artery bypass graft; COPD: chronic obstructive pulmonary disease; CVD: cardiovascular disease;

ECG: electrocardiogram; FEV $_{1}$ : forced expiratory volume during one second; FVC: forced vital capacity; GOLD: global initiative for chronic obstructive lung disease; IHD: ischemic heart disease; LBBB: left bundle branch block;

MC: Minnesota code; NLF: normal lung function; PCl: percutaneous coronary intervention; SVC: slow vital capacity; VC: vital capacity.

\section{Competing interests}

The authors declare that they have no competing interests.

\section{Authors' contributions}

All authors have substantially contributed in the process of writing the manuscript and approved the final version of the manuscript. In addition, UN is corresponding author and has contributed in interpretation of data and statistical analysis. BE contributed to data collection and interpretation of data. $\mathrm{BJ}$ and $\mathrm{AB}$ contributed to the interpretation of data. $\mathrm{BL}$ was responsible for the study design, together with AL. AL took part in data collection and interpretation of data. AL takes responsibility for the integrity of the data and the accuracy of the data analysis.

\section{Acknowledgement}

First, the authors thank Professor Eva Rönmark, the present head of the OLIN studies, for her support. Further, the authors thank the research assistants Ann-Christine Jonsson and Sigrid Sundberg for collecting the data. The authors also thank Helena Backman, the OLIN studies, and Fredrik Jonsson, Umeå University for statistical advice. Professors Abdonas Tamosiunas and Ricardas Radisauskas, Lithuanian University of Health Sciences, has been of great help with the Minnesota coding of the ECGs.

\section{Financial support}

The Swedish Heart- Lung Foundation, FoU Västerbotten County Council and The Heart Foundation of Northern Sweden are acknowledged for research funding.

\section{Author details}

${ }^{1}$ Department of Public Health and Clinical Medicine, Division of Medicine, Umeå University, Umeå, Sweden. ${ }^{2}$ Krefting Research Centre, Institute of Medicine, Sahlgrenska Academy, University of Gothenburg, Gothenburg, Sweden. ${ }^{3}$ Department of Public Health and Clinical Medicine, Division of Medicine, University Hospital of Northern Sweden, Umeå 90185, Sweden. 
Received: 13 August 2015 Accepted: 20 November 2015 Published online: 04 December 2015

\section{References}

1. Lindberg A, Bjerg A, Bjerg-Bäcklund A, Rönmark E, Larsson LG, Lundbäck B. Prevalence and underdiagnosis of COPD by disease severity and the attributable fraction of smoking Report from the Obstructive Lung Disease in Northern Sweden Studies. Respir Med. 2006;100(2):264-72.

2. Soriano JB, Ancochea J, Miravitlles M, García-Río F, Duran-Tauleria E, Muñoz L, et al. Recent trends in COPD prevalence in Spain: a repeated cross-sectional survey 1997-2007. Eur Respir J. 2010;36(4):758-65.

3. Gershon AS, Wang C, Wilton AS, Raut R, To T. Trends in chronic obstructive pulmonary disease prevalence, incidence, and mortality in ontario, Canada, 1996 to 2007: a population-based study. Arch Intern Med. 2010;170(6):560-5.

4. Finkelstein J, Cha E, Scharf SM. Chronic obstructive pulmonary disease as an independent risk factor for cardiovascular morbidity. Int J Chron Obstruct Pulmon Dis. 2009:4:337-49.

5. WHO: GLOBAL STATUS REPORTon noncommunicable diseases 2014 In.; 2014.

6. Lindberg A, Larsson LG, Muellerova H, Ronmark E, Lundback B. Up-to-date on mortality in COPD - report from the OLIN COPD study. BMC Pulm Med. 2012;12:1.

7. Decramer M, Rennard S, Troosters T, Mapel DW, Giardino N, Mannino $D$, et al. COPD as a lung disease with systemic consequences-clinical impact, mechanisms, and potential for early intervention. COPD. 2008;5(4):235-56.

8. Decramer M, Janssens W, Miravitlles M. Chronic obstructive pulmonary disease. In: Lancet. 379th ed. England: 2012 Elsevier Ltd; 2012. p. 1341-51.

9. Ukena C, Mahfoud F, Kindermann M, Kindermann I, Bals R, Voors AA, et al. The cardiopulmonary continuum systemic inflammation as 'common soil' of heart and lung disease. Int J Cardiol. 2010;145(2):172-6.

10. Cavailles A, Brinchault-Rabin G, Dixmier A, Goupil F, Gut-Gobert C, Marchand-Adam S, et al. Comorbidities of COPD. European respiratory review : an official journal of the European Respiratory Society. 2013;22(130): 454-75.

11. Mapel DW, Dedrick D, Davis K. Trends and cardiovascular co-morbidities of COPD patients in the Veterans Administration Medical System, 1991-1999. COPD. 2005;2(1):35-41.

12. de Lucas-Ramos P, Izquierdo-Alonso JL, Rodriguez-Gonzalez Moro JM, Bellon-Cano JM, Ancochea-Bermudez J, Calle-Rubio M, et al. Cardiovascular risk factors in chronic obstructive pulmonary disease: results of the ARCE study. Arch Bronconeumol. 2008:44(5):233-8.

13. Salisbury AC, Reid KJ, Spertus JA. Impact of chronic obstructive pulmonary disease on post-myocardial infarction outcomes. Am J Cardiol. 2007;99(5):636-41.

14. Campo G, Guastaroba P, Marzocchi A, Santarelli A, Varani E, Vignali L, et al. Impact of COPD on long-term outcome after ST-segment elevation myocardial infarction receiving primary percutaneous coronary intervention. Chest. 2013;144(3):750-7.

15. Engstrom G, Hedblad B, Janzon L. Reduced lung function predicts increased fatality in future cardiac events. A population-based study. J Intern Med. 2006;260(6):560-7.

16. Campo G, Pavasini R, Malagu M, Mascetti S, Biscaglia S, Ceconi C, et al. Chronic obstructive pulmonary disease and ischemic heart disease comorbidity: overview of mechanisms and clinical management. Cardiovasc Drugs Ther. 2015;29(2):147-57.

17. Lindberg A, Lundbäck B. The Obstructive Lung Disease in Northern Sweden Chronic Obstructive Pulmonary Disease Study: design, the first year participation and mortality. Clin Respir J. 2008;2 Suppl 1:64-71.

18. Jyrki-Tapani K, Sovijarvi A, Lundback B. Chronic obstructive pulmonary disease in Finland: prevalence and risk factors. COPD. 2005;2(3):331-9.

19. Lundback B, Stjernberg $N$, Rosenhall L, Lindstrom M, Jonsson $E_{\text {, }}$ Andersson S. Methacholine reactivity and asthma. Report from the Northern Sweden Obstructive Lung Disease Project. Allergy. 1993;48(2):117-24.
20. Lundback B, Stjernberg N, Nystrom L, Forsberg B, Lindstrom M, Lundback K, et al. Epidemiology of respiratory symptoms, lung function and important determinants. Report from the Obstructive Lung Disease in Northern Sweden Project. Tubercle and lung disease : the official journal of the International Union against Tuberculosis and Lung Disease. 1994;75(2):116-26.

21. Lundback B, Ronmark E, Jonsson E, Larsson K, Sandstrom T. Incidence of physician-diagnosed asthma in adults-a real incidence or a result of increased awareness? Report from The Obstructive Lung Disease in Northern Sweden Studies. Respir Med. 2001;95(8):685-92.

22. Reid DD, Hamilton PJ, McCartney P, Rose G, Jarrett RJ, Keen H. Smoking and other risk factors for coronary heart-disease in British civil servants. Lancet. 1976;2(7993):979-84

23. American Thoracic Society. Standardization of Spirometry, 1994 Update. Am J Respir Crit Care Med. 1995;152(3):1107-1136.

24. From the Global Strategy for the Diagnosis, Management and Prevention of COPD, Global Initiative for Chronic Obstructive Lung Disease (GOLD) 2015. Available from: [http://www.goldcopd.org].

25. Backman $H$, Lindberg A, Sovijärvi $A$, Larsson $K$, Lundbäck $B$, Rönmark $E$. Evaluation of the global lung function initiative 2012 reference values for spirometry in a Swedish population sample. BMC Pulm Med. 2015;15(1):26.

26. Backman $H$, Lindberg A, Odén A, Ekerljung L, Hedman L, Kainu A, et al. Reference values for spirometry - report from the Obstructive Lung Disease in Northern Sweden studies. Eur Clin Respir J. 2015;2:26375.

27. Mullerova H, Agusti A, Erqou S, Mapel DW. Cardiovascular Comorbidity in COPD Systematic Literature Review. Chest. 2013;144(4):1163-78.

28. Lange P, Mogelvang R, Marott JL, Vestbo J, Jensen JS. Cardiovascular morbidity in COPD: A study of the general population. COPD. 2010;7(1):5-10.

29. Johannessen A, Omenaas ER, Bakke PS, Gulsvik A. Implications of reversibility testing on prevalence and risk factors for chronic obstructive pulmonary disease: a community study. Thorax. 2005;60(10):842-7.

30. Methvin JN, Mannino DM, Casey BR. COPD prevalence in southeastern Kentucky: the burden of lung disease study. Chest. 2009;135(1):102-7.

31. Mannino DM, Buist AS, Petty TL, Enright PL, Redd SC. Lung function and mortality in the United States: data from the First National Health and Nutrition Examination Survey follow up study. Thorax. 2003;58(5):388-93.

32. Curkendall SM, DeLuise C, Jones JK, Lanes S, Stang MR, Goehring Jr E, et al. Cardiovascular disease in patients with chronic obstructive pulmonary disease, Saskatchewan Canada cardiovascular disease in COPD patients. Ann Epidemiol. 2006;16(1):63-70.

33. Maclay JD, McAllister DA, Mills NL, Paterson FP, Ludlam CA, Drost EM, et al. Vascular dysfunction in chronic obstructive pulmonary disease. Am J Respir Crit Care Med. 2009;180(6):513-20.

34. Vivodtzev I, Tamisier R, Baguet JP, Borel JC, Levy P, Pepin JL. Arterial stiffness in COPD. Chest. 2014;145(4):861-75.

35. Qvist L, Nilsson U, Johansson V, Larsson K, Rönmark E, Langrish J, et al. Central arterial stiffness is increased among subjects with severe and very severe COPD - report from a population based cohort-study. Eur Clin Respir J. 2015;2:27023.

36. Campo G, Pavasini R, Pollina A, Tebaldi M, Ferrari R. On-treatment platelet reactivity in patients with chronic obstructive pulmonary disease undergoing percutaneous coronary intervention. Thorax. 2014;69(1):80-1.

37. Vestbo J, Edwards LD, Scanlon PD, Yates JC, Agusti A, Bakke P, et al. Changes in forced expiratory volume in 1 second over time in COPD. $N$ Engl J Med. 2011;365(13):1184-92.

38. Eriksson B, Lindberg A, Mullerova H, Ronmark E, Lundback B. Association of heart diseases with COPD and restrictive lung function-results from a population survey. Respir Med. 2013;107(1):98-106.

39. Okura Y, Urban LH, Mahoney DW, Jacobsen SJ, Rodeheffer RJ. Agreement between self-report questionnaires and medical record data was substantial for diabetes, hypertension, myocardial infarction and stroke but not for heart failure. J Clin Epidemiol. 2004;57(10):1096-103.

40. Shah A, Wagner GS, Green CL, Crater SW, Sawchak ST, Wildermann NM, et al. Electrocardiographic differentiation of the ST-segment depression of acute myocardial injury due to the left circumflex artery occlusion from that of myocardial ischemia of nonocclusive etiologies. Am J Cardiol. 1997;80(4):512-3. 
41. Michael MA, El Masry H, Khan BR, Das MK. Electrocardiographic signs of remote myocardial infarction. Prog Cardiovasc Dis. 2007:50(3):198-208.

42. Celli BR, MacNee W, Force AET. Standards for the diagnosis and treatment of patients with COPD: a summary of the ATS/ERS position paper. The European respiratory journal : official journal of the European Society for Clinical Respiratory Physiology. 2004;23(6):932-46.

Submit your next manuscript to BioMed Central and we will help you at every step:

- We accept pre-submission inquiries

- Our selector tool helps you to find the most relevant journal

- We provide round the clock customer support

- Convenient online submission

- Thorough peer review

- Inclusion in PubMed and all major indexing services

- Maximum visibility for your research 